mental pitfalls associated with the application of the powder X-ray diffraction technique to the identification of organic crystalline materials are indicated. The chapter contains an excellent survey of fundamental crystal optics, morphology, use of Miller indices, etc.

Neilands contributes a welcome review chapter on enzymes, their availability and their varied analylytical and clinical usages. He supplies a valuable bibliography of specific applications, for example, estimation of ethanol in blood, detection of peroxides, analysis of specified amino-acids, etc.

The wide use of organic peroxides and ozonides by many industries has resulted in the production of a timely review by Martin on the determination of these occasionally hazardous reagents. The adventitious formation of peroxides in ether solvents is discussed, and the use of an activated alumina column for solvent desensitization and purification is worthy of note.

Iodometric, colorimetric, polarographic, infra-red and other related techniques for peroxide determination are described in reasonable detail, and some attention is paid to the estimation of peroxide mixtures using chromatographic or counter-current distribution separation procedures. Analytical interferences produced by sulphur compounds, conjugated diolefins, aldehydes, etc., are defined: the polarographic method of analysis is considered the most widely applicable method for peroxides generally.

The present volume ends with a chapter by $\mathrm{Ke}$ on the applications of differential thermal analysis to the examination of high polymers. The apparatus is described fully, and the thermograms are interpreted in terms of conventional thermodynamic parameters. Applications of this powerful technique to work on synthetic and natural polymers are clearly and extensively demonstrated.

This new volume of the Organic Analysis series will undoubtedly be as eulogistically received as were its predecessors. It presents, in a small compass, a considerable amount of information on the theoretical and practical aspects of the six important subjects reviewed, and provides material which will undoubtedly be of the greatest interest to the industrial chemist, the research worker and the academic student.

D. T. LEwIS

\section{STILL MORE NUCLEIC ACIDS}

The Nucleic Acids

Vol. 3. Edited by Erwin Chargaff and J. N. Davidson. Pp. xvi + 588. (Now York : Academic Press, Inc.; London: Academic Press, Inc. (London), Ltd., 1960.) 18 dollars. $W_{\text {published, it was evident to the editors that the }}^{\text {HEN the first two volumes of this book were }}$ research on this subject was expanding rapidly, but even they did not anticipate the explosion which has since followed. In an attempt to bring their treatise up to date, they have now issued Volume 3 , which has as its object the covering of certain aspects of the subject which had been neglected in the original volumes, or which have recently assumed particular importance. The editors should be congratulated on their decision to take this course, and the third volume of this series will certainly prove a valuable addition to many libraries. They might, however, consider at this time whether it would not be more useful to begin a new series, similar to Advances in
Protein Chemistry, which would provide definitive articles on recent aspects of the subject and not involve so much delay in publication, rather than to continue this series. It is certainly unlikely that the compiling of a comprehensive and up-to-date textbook on nucleic acids will be feasible for many years.

The new volume is a sort of compromise between a text-book and a review. All the contributors are actively engaged in research on the subjects covered in their contributions, and while this certainly makes for authoritative articles, there is the concomitant risk of the authors giving a one-sided view of the subject. For example, someone reading Schuster's article on virus ribonucleic acids might get the impression that research on this subject began about 1954, whereas the pioneering work of Bawden and Pirie, who first discovered ribonucleic acids in a number of plant viruses some twenty five years ago, is not referred to, though some of their later work is. Max Schlesinger, a neglected pioneer if ever there was one, is not even mentioned in an otherwise admirable chapter on bacteriophage nucleic acids written by Sinsheimer, though Schlesinger was not only the first person to purify a bacteriophage but was also the first person to identify nucleic acid in any virus. Sinsheimer devotes tantalizingly little space in this article to his own work on the singlestranded deoxyribonucleic acid of the bacteriophage $\varphi X 174$, which demonstrates quite convincingly that complementary filaments of deoxyribonucleic acid are not essential for the transfer of genetic information.

Sadron's contribution is largely devoted to lightscattering and hydrodynamical methods of investigat. ing nucleic acids which do not have enough resolving power for polydisperse solutions. However, some of the problems which he poses have since been solved by the elegant methods of Meselson and his colleagues, which unfortunately are too recent to have been included in this chapter, though they are touched on elsewhere. The photochemistry of nucleic acids is covered in considerable detail by Shugar, who also provides a useful list of recommended volumes for extra reading. Khorana reviews both the chemical and enzymic synthesis of polynucleotides, a subject to which he has contributed so much, both directly and by his synthesis of substrates, but surprisingly he omits mention of the enzymic synthesis of small polynucleotides by the reversal of the action of ribonucleases.

The chapter by Hoagland on nucleic acids and their involvement in protein synthesis is most welcome as an authoritative review of this important work, much of which has come from his laboratory, while Gros describes related happenings in bacteria.

The effects of 'antimetabolites' on nucleic acid metabolism, which a few years ago gave so much hope, unfortunately unrealized, of a rational approach to the control of many serious diseases, are covered by Handschuhmacher and Welch. Unexpectedly, this work has made a real contribution to our knowledge of nucleic acid metabolism which could scarcely have been obtained by other means.

A compendium of the analyses of microbial nucleic acids is given by Belozersky and Spirin (it is most encouraging to see a contribution from the U.S.S.R.), and the biosynthesis of purine and pyrimidine nucleotides is covered by Buchanan and Crosbie respectively. Finally, Lajtha gives a short review of the effects of ionizing radiations on nucleic acid metabolism.
ROY MARKHAM 